\title{
Conexión discursiva en medios de comunicación escrita: educación, valores y deporte
}

\author{
Roberto CACHÁN CRUZ \\ Universidad de León \\ rocacruz@hotmail.com \\ Óscar FERNÁNDEZ ÁLVAREZ \\ Universidad de León \\ Oscar.fernandez@unileon.es
}

Recibido: 01/08/2011

Aceptado: 30/01/2012

\section{Resumen}

Este trabajo analiza los discursos generados por medios de comunicación escrita referidos a noticias deportivas de ámbito nacional entre 2008 y 2010. El objetivo central de la investigación es analizar y explicar cómo las noticias deportivas transmiten valores como esfuerzo y superación, pero también contravalores, como lucha y agresividad que, en principio, podrían ser considerados poco pedagógicos. La metodología empleada parte del análisis crítico del discurso (ACD) aplicado en las noticias mencionadas. Se han elaborado unas categorías para clasificar y analizar la transmisión de valores. Se ha validado la propuesta a través de 400 alumnos en I.E.S. de Castilla y León (España). Los resultados de la investigación concluyen que los medios de comunicación, aproximan más que notablemente la realidad deportiva y mítica simbólica, en su componente pedagógico-educativo.

Palabras clave: Media; Deporte; Educomunicación; Análisis crítico del discurso; Simbolismo

\section{Discourse Connections in the Written Media: Education, Values and Sport}

\begin{abstract}
This article analyses the discourse produced by written media in regard of sports news in Spain between 2008 and 2010. The objective of the research was to investigate and explain the ways in which values, such as effort and striving to better one's performance, are represented through the sports news, but also countervailing attitudes, such as struggle and aggressiveness. The method that was used began with a critical discourse analysis (CDA) applying to sports news press with the largest print runs. A number of categories were drawn up that permitted classification and analysis of the transmission of those values. This approach was validated by a survey of 400 pupils in various secondary schools in Castile and Leon (Spain). The results of the research conclude that these media bring together sports reality and symbolic myths, in their pedagogical and educational aspects, to a very striking extent.
\end{abstract}

Keywords: Media; Sport; Educational communication; Critical discourse analysis; Symbolisms

\section{Referencia normalizada}

CACHÁN CRUZ, Roberto y FERNÁNDEZ ÁLVAREZ, Óscar (2012): “Conexión discursiva en medios de comunicación escrita: educación, valores y deporte”. Estudios sobre el mensaje periodístico. Vol. 18, núm. 1, págs.: 293-304. Madrid, Servicio de Publicaciones de la Universidad Complutense.

Sumario: 1. Introducción. 2. Metodología. 3. Resultados. 4. Análisis e interpretación del contenido. 5. Conclusiones. 6. Referencias bibliográficas.

\section{Introducción}

La repercusión del deporte en la sociedad actual es enorme, y eso se transfiere a los centros educativos y a sus alumnos. Parece claro que el deporte y su significación social no tendrían trascendencia social si no fuera por los medios de comunicación. Por 
otra parte, está ampliamente asumido que el deporte es un recurso educativo para la educación y transmisión de valores. Sin embargo, hoy en día, como plantea GINESTA (2007: 149) no podemos pensar que los valores asociados a la práctica deportiva son todos positivos. Pero el tema es aún más complejo, si a esto añadimos la necesaria conciliación de los medios de comunicación y los valores, tanto positivos como negativos, como los propios medios, que amplifican y expanden sus virtudes, defectos, marcas, resultados y su manera de actuar, que al fin y al cabo, proyectan los valores que rigen sus vidas personales y profesionales.

La construcción de una industria del ocio y cultura vinculada al deporte no hubiera sido posible sin la intervención simultánea de un producto genuinamente novedoso en su momento, como fue la prensa popular deportiva, que compitió entre sí por ofrecer antes que nadie los resultados de partidos, apuestas y carreras. Su contenido, tratamiento, estilo y lenguaje fueron también diferentes. Así por ejemplo, la prensa deportiva inglesa, como nos dice WiLLIAMs (1984: 198), en la segunda mitad del XIX obedeció a un lenguaje cuidado y con referencia a lo clásico. Hacia 1890 se otorga importancia a un lenguaje más rudo. El ejemplo más claro que señala fue el Daily Mail, que en 1900 alcanzó una tirada de millón y medio de ejemplares, y a medio penique, era una imitación consciente del The Times, dirigida a un público diferente.

Pero no abundan los estudios que analicen a fondo el contenido de la prensa deportiva actual, aunque si el uso de los medios de comunicación y su vinculación con el deporte, sobre todo como transmisores de valores. Así por ejemplo, GARCíA MATILLA (2001) hace una propuesta para el aprovechamiento didáctico del fútbol televisado como metáfora mediática de la realidad y explora las posibilidades formadoras del fútbol y de sus protagonistas. GINESTA (2007) plantea una educación en valores a través de la rivalidad en un derbi clásico en el fútbol español, para evitar rivalidades y enfrentamientos. Pero hoy en día, está fuera de toda duda que hay elementos en los medios de comunicación contemporáneos dispuestos a crear más discursos de guerra que discursos de paz. Como apunta SHINAR (2000: 91), desde el punto de vista de la mayoría de las distribuidoras comerciales de comunicación, "la paz es aburrida". A este respecto, ya en 1986 y con motivo de los incidentes de Heysel ${ }^{1}$, Young (1993) analizó el contenido de la prensa deportiva agrupando titulares por la culpabilidad, el comportamiento irracional y carente de sentido, las cualidades deshumanizadoras o el lenguaje de guerra. Si se ha constatado literatura deportiva en la que se establecen discursos con temática mítica, ritual y simbólico-religiosa² ${ }^{2}$

${ }^{1}$ El 29 de mayo de 1985, en el estadio de Heysel (Bruselas) tuvo lugar la Final de la Copa de Europa de Fútbol entre la Juventus de Turín y el Liverpool, con resultado de 39 muertos y multitud de heridos. El incidente fue tan noticiable que empequeñeció a otros, como los que describían los cientos de miles de personas muertas en un ciclón ocurrido en Bangladesh en las mismas fechas.

${ }^{2}$ La dimensión religiosa en productos, acciones, organizaciones comerciales como Walt Disney o los McDonalds, el fútbol, la propaganda y otros aspectos de la cultura norteamericana, ha sido analizada por KoTTAK (1997: 247 y ss.), concluyendo que son afines en un comportamiento ritual, mitológico y simbólico. De análoga forma, nosotros hemos podido 
Así, esta investigación parte de la constatación de la hipótesis de que los medios de comunicación construyen una serie de creencias, sentimientos y modos de comportamiento colectivos que identifican y se vivencian en forma de ritual, incitando a una especifica orientación hacia lo mítico.

\section{Metodología}

El estudio se ha realizado mediante el denominado análisis crítico del discurso (ACD) aplicado a la información contenida en los medios de comunicación. Este método nos permite observar la relación existente entre discurso y sociedad (DIJK, 1999 y 2000), relación necesaria pues consideramos los medios de comunicación como medios de formación y educación. Para analizar las funciones sociales de un discurso es necesario estudiar en qué estructuras lingüísticas se concreta esa influencia recíproca entre discurso y sociedad, porque como dice MEYER (2003: 35), el ACD, como perspectiva de investigación no debe entenderse como un método único sino más bien como un enfoque, desde el que adquieren consistencia varios planos simultáneamente. De esta forma, el discurso es concebido, por un lado, como un producto "susceptible de revelar determinados contenidos subyacentes, visiones del mundo, opiniones, ideologías" y, por otro, como un instrumento "capaz de proyectar esos contenidos en las representaciones sociales o individuales de las personas".

Un ejemplo muy revelador en esta intención de aunar lo social y lo comunicativo a través del análisis de lo lingüístico, lo encontramos en las estrategias discursivas que plantea el enfoque histórico-discursivo de Ruth WODAK (MEYER \& WODAK, 2003) y WeISS y WODAK (2002), que incluye la estrategia referencial, de nominación, en la que los dispositivos de interés son la categorización de la pertenencia, que para nuestro caso podemos asimilar a los criterios de identidad; las metáforas, las metonimias y las sinécdoques; las estrategias de intensificación y mitigación, etc.

Por otra parte, una de las características básicas del ACD es la necesidad de integrar conocimientos procedentes de otras disciplinas para ofrecer una visión completa y adecuada de su objeto de estudio, lo que equivale a un principio de interdisciplinariedad. En nuestro caso, esto supone la inclusión de conceptos de las disciplinas de procedencia de los autores de este trabajo, Antropología social en diferentes ramas como educativa, lingüística, visual y religiosa, y las Ciencias de la Actividad Física y Deportiva.

comprobar cómo la publicidad deportiva en España se ha valido de toda una simbología religiosa, bélica, legendaria, para llegar al producto (videos, spots, videojuegos), y sirvan como ejemplos, los siguientes: monjes jugando al fútbol en el monasterio de Uclés (campaña de Nike de 1990); Ángeles y demonios luchando por la salvación (campaña de Nike de 1995) en una especie de ritual batalla de fútbol, en un campo que ejerce de infierno; escenarios industriales y catacumbas en un choque entre deportistas, (campaña Nike de 2007); Duelo y supervivencia (Secret Tournemant), en un barco abandonado en medio del océano enfrentando figuras del deporte (campaña Nike de 1998); The Mission (Nike), etc. Otros productos conexionan con una lógica guerrera: vikingos-Fernando Alonso (campaña de 2007), competición ceremonial entre gladiadores (campaña de Adidas de 2006), o el Real Madrid en el Chinchón western (campaña de Pepsi de 2006), la presentación de la Champions League de 2009 y 2010 con escenarios bélico-mitológicos, como el Partenón y el Coliseo. 
El procedimiento empleado comprendió tres fases. En la primera se efectuó el estudio sobre la información en prensa, que emerge de una experiencia formativa del área de Educación Física y Deportiva con alumnos de tercero y cuarto de la E.S.O., en diversos I.E.S. de Castilla y León durante los cursos 2008-2009 y 2009-2010, donde se analizaba de forma descriptiva, las noticias deportivas. Se trataba de poner de manifiesto los objetivos generales de la etapa y del área en el segundo ciclo de la E.S.O. Los continuos cambios en el marco legal educativo español han contribuido a situar la competencia de comunicación lingüística y tratamiento de la información y la competencia digital como eje nuclear. Así, específicamente, los artículos 19, 24 y 26 de la Ley Orgánica de Educación de 2007, establecen que la lectura deberá ser trabajada desde todas las áreas. Esta fue una razón más a la hora de utilizar la prensa escrita, que tiene un público que abarca todas las edades, a diario y realizado bajo un prisma más profundo, pese a la vehemencia de otros medios. Y es que, como explica Moragas (1995:268), "la limitación de la lectura y su sustitución por imágenes o por textos interactivos, que son necesariamente breves y sintéticos, puede facilitar el empobrecimiento del debate y de las reflexiones sobre la realidad social, política o cultural".

En este nivel de análisis mediático se buscaba lo enunciativo, lo temático y lo retórico. La muestra analizada comprende la información deportiva contenida en prensa escrita según el plan ya mencionado. No obstante, debido a su extensión nos hemos limitado a la sección de deportes de prensa generalista de mayor tirada según la OJD (El País, El Mundo y $A B C$, principalmente), y prensa deportiva especializada (Marca, As, Sport y El Mundo Deportivo). Nos centramos en la prensa de los domingos y lunes, por ser los días de crónicas, competición y juicios deportivos. El periodo seleccionado tiene gran interés porque coincide con momentos muy intensos de competiciones deportivas. Así, en 2008 se celebró la Eurocopa de Fútbol, la Champions, los Juegos Olímpicos de Pekín; durante 2009, la más que ilustrativa y mesiánica presentación de los futbolistas Kaká y Cristiano Ronaldo en el Real Madrid; y durante 2010, la Copa Confederaciones y el Mundial de Fútbol. Se trabajó con cerca de 1.600 noticias.

En la segunda fase se realizó un análisis de gabinete de la información recogida y nos permitió elaborar ocho categorías o líneas temáticas donde se pone de manifiesto propiamente la transmisión de valores a través de la prensa deportiva.

En la tercera se hizo un análisis de la información encuadrándola en el marco teórico de referencia, a partir del cual se elabora la discusión e interpretación que mostramos posteriormente.

\section{Resultados}

Para un mejor tratamiento de la información obtenida y de los discursos que aparecen en la prensa en torno al deporte, y con un orden de presencia ascendente, hemos elaborado las siguientes categorías, que ilustramos con una serie ejemplos para su mejor comprensión.

a) Dolor y sufrimiento: "las lágrimas de San Iker"; "ha decidido estar abonado al sufrimiento"; "miércoles negro"; "sufrir y sufrir hasta el final"; "jornada de penitencia"; "Fiesta en el funeral"; "sufre para ganar"; "con sangre, sudor y lágrimas"; etc. 
b) Bélico: Los registros bélicos convergen entre lo violento y lo religioso, aunque los registros y metáforas militares también son abundantes como "ataque"; "cañonero"; "K.O."; "misión cumplida"; "zafarrancho"; "bajar la guardia"; "tirar la toalla"; "tumbar"; "noquear"; "fortín" o "visto para sentencia". El deporte se usa como arma diplomática y en ocasiones los enfrentamientos deportivos se han convertido en ritos que subliman los enfrentamientos bélicos: la mano de Dios de Maradona es tan recordada porque funciona a modo de venganza virtual de los argentinos sobre los británicos por la ofensa de la guerra de Las Malvinas. Sirva como ejemplo, y razón que enfatice y vincule lo bélico con lo religioso.

c) El azar y la providencia: "toda una vida en 90 minutos"; "un partido para vivir o morir"; "el partido de nuestras vidas"; "sólo queda un milagro"; "el milagro pasa por ganarlo todo y rezar"; "Ya se sabe que la fe hace milagros"; "Hay que vender el Palacio de la Magdalena para ficharlo"; "muestra el camino"; "La diosa fortuna se encarga de decidir a qué rivales se tiene que enfrentar"; "La gloria, siempre efímera"; "el bombo 2 albergará esperanzas"; etc.

d) Lenguaje místico, fabuloso, mitológico y legendario: "visita a su bestia negra"; "inicia su periplo europeo"; "fue el canto del cisne para un equipo que depende en exceso"; "El maratoniano viaje, al final, mereció la pena"; "Contra los elementos"; "Ahora se reverdecen laureles"; "Llegamos a esta Copa por la puerta de atrás y al final salimos por el arco de triunfo"; "apelar a lo épico"; "tiene mil cabezas y nunca muere"; "Otra palada de arena"; "Maratón de partidos"; "llega al infierno"; "La guarida del lobo"; etc.

e) Préstamos semánticos y fraseología de origen bíblico: "Debut ante un lobo con piel de cordero"; "hacer leña del árbol caído"; "cara o cruz"; "Amargas e inmerecidas tablas"; "remontó hasta firmar tablas con los franceses en el tramo final"; "Comienza la diáspora de jugadores con sus selecciones"; "una bella historia de David contra Goliat"; "no tuvo piedad con el rival"; "se preparó el Belén"; "pero en el cara o cruz final alguna decisión arbitral y la suerte estuvieron"; "un camino de espinas"; "se han quedado con el santo y la limosna"; "El día de la bestia"; etc.

f) Santificaciones, glorificaciones y mitificaciones: "un rosario de nombres para la historia"; "Un triunfo dedicado al cielo"; "y le puso una estampita"; "el resurgir de"; "Super Iniesta"; "San Iker"; "merecían una estatua"; "adiós a uno de sus mayores mitos".

g) Creencia en seres o fuerzas místicas: "Como no tienen la magistral pócima de Astérix y Obélix, que los hace invencibles"; "marcado por una cruz"; "milagro en la portería"; "enterrar sus fantasmas"; "necesitan ahora, más que nunca, todo el aliento de la grada"; "cruzo los dedos para que no sea una lesión grave"; "un espejismo"; "cuando el partido se igualó volvieron los miedos"; "el equipo sepulta sus fantasmas"; etc.

h) Alusiones a la supervivencia e inmortalidad: "el sempiterno"; "quiere volver a respirar"; "todavía estamos vivos en Europa"; "el equipo quiere sepultar la racha de derrotas"; "Semana de resurrección"; "con un gol en el último suspiro"; "triunfo cómodo que sabe a esperanza". 


\section{Análisis e interpretación del contenido}

Vistas las distintas categorías elaboradas, podemos observar que existe un equilibrio entre el lenguaje bélico y del sufrimiento con respecto a las demás categorías. Un equilibrio que discurre primero, por el número de noticias observadas y segundo, desde la valoración cualitativa, porque la temática bélica o guerrera se encuadraría dentro de las estrategias educativas y formativas. Así, a través de este lenguaje de guerra se identifica una forma de autoafirmación controlada que proyecta la superación personal, exalta virtudes y pregona un bien común. De manera paradójica, el lenguaje bélico otorga al deporte el papel de reconductor de sentido, porque como dice SÁNCHEZ \& SÁNCHEZ (2001: 33), "es un aparato semántico básico en la transmisión de valores", más si cabe en un contexto de crisis social, política, cultural e ideológica. Hemos observado que dos conceptos, bélico y educativo, a priori tan disímiles, a través de su mensaje y su correlación, han creado una valoración positiva de los medios de comunicación. E influye activamente en la conducta de quien lo lee, lo sigue o lo profesa. Este eje semántico instructivo o dogmático-militar no viene de ahora ya que según muestra Moscoso (2005: 79), al atleta-soldado de las polis griegas ya se le conferían atributos guerreros y de prestigio político y social. Es decir, el deportista héroe transmitía conciencia cívica en un momento en que era necesario reclutar soldados y guerreros a la vez que exaltar sus virtudes. La aproximación de estas concepciones al lenguaje deportivo se hace oportuna y necesaria sobre todo a un público joven, que va a ser futuro en generaciones posteriores. Por otro lado, eso nos lleva a plantear la figura del jugador héroe en el sentido de los valores que puede otorgar como santidad moral, sacrificio, férrea disciplina ante la falta de cultura del esfuerzo y la vigente búsqueda del éxito inmediato.

El hecho de identificar en la prensa las analogías religiosas y bélicas no se deslindan en su significado sino que nos hace pensar en una reformulación de contenidos, conjugando mecanismos cognitivos y educativos que deben interpretar los alumnos.

Quizá el ejemplo más reciente lo tenemos en el Premio Príncipe de Asturias concedido a la selección española de fútbol. Su entrenador, Vicente del Bosque, afirmó que el equipo, campeón mundial y ganador del galardón del Deporte, "ha hecho de la modestia un arma tan poderosa como su mismo y arrebatador juego", en alusión al "esfuerzo, el sacrificio, el talento, la disciplina, la solidaridad y la modestia", (El País, 2210-2010). Igualmente, el Príncipe de Asturias señalaba que «la selección española de fútbol ha puesto de manifiesto valores como "voluntad y tesón, máxima deportividad y humildad. La ejemplaridad de la selección española de fútbol es el mejor regalo que les habéis ofrecidos a los niños". Las cuestiones referidas al lenguaje de guerra, con su actitud de mano tendida, ha provocado un efecto tranquilizador, inmediato y revulsivo para un público necesitado.

Por otra parte, hemos observado que la representación que hacen los medios de comunicación sobre el deporte incide fuertemente en los imaginarios que crean es sus audiencias, lo que demanda una preocupación por proponer espacios de interacción cultural vinculados con la educación, la comunicación y el fenómeno mítico, simbólico y ritual, o religioso entendido en sentido amplio, Durkheniano (DURKHEIM, 1982), donde esos elementos se relacionan para ofrecer alternativas de encuentro, comuni- 
cación y acción entre diferentes grupos receptores de la información. Señalamos a continuación algunos ejemplos:

En lo concerniente a lo simbólico-ritual, el deporte se nos presenta como dispositivo para compararlos con otras parcelas del sistema: separaciones, liminalidad, discursos y prácticas, rutinas corpóreas o status, en un contexto específico que no hace más que amplificar el estudio del ritual más allá de los contextos antropológicos más tradicionales. A través de titulares y noticias donde aparecen expectativas de triunfo se intenta atraer la atención del lector con un merecido trabajo o victoria: "La gloria para el mejor" (El País, 30/06/2008:56); "me siento un guerrero con las pinturas" en la presentación de la camiseta en la Copa de Confederaciones ( $A B C, 25 / 03 / 09)$; "la fe de los jugadores" (Marca, 30/06/2008:12); o bien, desvelándose promesas de todos los jugadores como "raparse, teñirse el pelo o casarse" (Marca, 1/07/2008:16-17).

Por otro lado son destacables los rituales de ofrenda: "Pochettino le pide la salvación a la Virgen de Montserrat", cuando jugadores y el preparador del Español de fútbol subieron doce kilómetros hacia la Virgen, con plegaria incluida para eludir el descenso (Marca, 25/03/09:23); "Güiza prometió ir de la Eurocopa al altar" (Marca, 30/06/2008:40); "si ganamos la Eurocopa hago el Camino de Santiago" (Marca, 30/06/2008:40). Marta Domínguez, con su obtención de la medalla de oro del Campeonato del Mundo, hace ofrenda al Cristo de la Misericordia de Palencia y "se comprometió con fe, esperanza y amor" (El Mundo, 15/09/09).

La santidad o virtudes patrióticas que generan los periodistas son los principales argumentos para afianzar las claves en el camino hacia el ascenso o triunfos: "España se hace eterna con Luis" (El País, 30/06/2008:56); "hasta en el cielo se sabía" (Marca, 30/06/2008:7); "del cielo al paraíso" (Marca, 30/06/2008:45); "la magia de los héroes superbajitos" ( $A B C, 30 / 06 / 2008: 83)$; "De los insultos al éxtasis" (La Vanguardia, 30/06/2008:46-57); "Alá ya ha decidido el destino de la final de la Champions" ( $E l$ Mundo, 26/05/09:41); "En el Barça, Messi no ha necesitado permiso de Dios" (Marca, 26/05/08); "El Barcelona invoca la eternidad" $(A B C, 27 / 05 / 09)$; "un equipo eterno", (ABC, 28/05/09); "La profecía de Guardiola sobre el gol de Messi" (Sport, 28/05/09); "Los dioses pisan el césped; Las ceremonias de masas confirman al fútbol como una nueva religión; El mesianismo afecta a las estrellas del deporte y del espectáculo" ( $E l$ Pais, 12/07/09:42-43); "Doce dioses para La Cibeles" (El Mundo, 22/09/09).

Otro aspecto destacable lo vemos cuando se hacen recordatorios a jugadores desaparecidos como Puerta o Arconada (Marca, 30/06/2008:8); o al mito: "Pujol, Capitán de capitanes, mito", "corona sin espinas" (El Mundo deportivo, 28/05/09); "Gasol, el Olimpo del basket" (Sport, 16/06/2009); o "Gasol se gana la eternidad" (El País, 16/06/2009); y como en toda mitificación, oculta transformando el sentido del objeto mediante una asociación de significados que apuntan a lo sagrado y trascendente, tal y como nos recuerdan ARMENTIA, CAMINOS \& MARTín (2005: 97).

La creencia en fuerzas sobrenaturales, actúan como germen de moralidad de las personas religiosas. Y los actores deportistas los utilizan para jugar con la suerte. NEIL, ANDERSON \& SHEPPARD (1981) ya demostraron que cuanto mayor es el nivel de la competencia y mayor el compromiso en un deporte, más prevalece la superstición. En los medios de comunicación son más que considerables las articulaciones entre la 
cosmología deportiva y el mundo mágico-religioso. De entrada, llama la atención la maldición en torno a la superstición y a los maleficios. Por ejemplo la cosmovisión en torno a los números aparece en constantes discursos y dan una visión más que trascendente. En la prensa se refleja que es común evitar un dorsal por el acopio de lesiones e intervenciones quirúrgicas, pero sobre todo se asocia a alguien mítico que lo llevó: "el United se somete a la religión del 7"; "Los dioses del fútbol" $(A B C$, $28 / 05 / 09)$. Esto nos sirve de ejemplo para ver que la superstición aparece debido a los numerosos riesgos y contingencias que lleva implícito el oficio de deportista-héroe (MORRIS, 1982:116).

Las supersticiones actuales, aunque parezcan descabelladas no se alejan de las de antaño. Implican a menudo la perfección la pureza, el orden, el color o la simetría. Es muy común leer el "12 más uno", "los números hablan", "miércoles negro", "antes de entrar me santiguo" o "entro con el pie derecho", etc. Ya lo aseveraba Sebreli (1998: 233 y ss.) cuando expresaba que el deporte, al igual que la religión, se mezcla frecuentemente con la superstición pseudo-cabalística, concluyendo que "si la religión y la magia están en el origen del juego, podemos ver que una evolución circular llevará a su vez al juego a transformarse en religión". De la misma forma, el tema del cuerpo ha sido trascendental en los rituales deportivos, expresado y formalizado en banderas, fetiches, tatuajes, amuletos, ritos corporales o de vestuario, según BURKETT (2009: 289), aparecen como estrategias para controlar el comportamiento del cuerpo. Así por ejemplo, Kaká, jugador del Real Madrid, pertenece a la asociación de cristianos evangélicos y en las lengüetas de sus zapatillas figura "Dios es fiel", en su camiseta interior lleva escrito "I belong to Jesus" y aprovecha cuando marca un gol para lucirlo. La prensa se ha hecho eco en múltiples ocasiones.

El periódico La Razón, en un reportaje titulado El fútbol también cree en Dios, publicado el 19 de mayo de 2004, señalaba numerosos casos que hoy también se leen: El liberiano Weah, musulmán practicante, se recogía en oración durante un minuto antes de cada partido. El evangélico Chamot, del Milán, regalaba Biblias a los rivales. Amoroso, también evangélico, celebraba los goles en el Udinese mostrando en la camiseta "Gracias, Dios". Ronaldo se declara creyente católico, recordando públicamente el encuentro con el Papa. El nigeriano Kanu admite tener una experiencia trascendental. Javier Irureta, ex-entrenador del Deportivo dice ir a misa todos los domingos y hacía rezar un Padre nuestro a los jugadores antes de entrenar en agradecimiento por haber ganado una Liga Española. Y si debemos paramos a reflexionar en una noticia de trascendencia religiosa, esa es la presentación de Kaká y de Cristiano Ronaldo en el Real Madrid en julio de 2009 con titulares como: "Dios Cristiano" (Última Hora de Palma de Mallorca, 7/07/09:46); "El nuevo cristianismo" (ABC, 6/07/09); "Un dios que reza a Dios" (Diario de León, 1/07/09); o "Kaká, el auténtico mesías" (Eurosport, 6/07/09).

Un suceso más que significativo es el miedo escénico, concepto acuñado por VALDANO (1986: 103-109), considerando así a un hipotético equipo y en momento de transitoria crisis deportiva, al enfrentarse, al equipo que había sido vencido siempre en los últimos años. Así lo contempla la prensa rogando confianza al mismo destino, en una especie de protección mágica: "El Palacio de los fantasmas" (El País, 27/04/09); o la 
repetida "cancha talismán". Las continuas predicciones del pulpo Paul en el reciente Mundial del Futbol (El Mundo Deportivo, 6/7/10) también dan prueba de ello.

La imputación de culpa a algo inmaterial no escapa a las intenciones periodísticas ni a las argumentaciones de técnicos y dirigentes, y por afinidad, a peñas y aficionados. Algunos ejemplos recogidos en la prensa son: "derrota en su cancha maldita"; "se acabó con el gafe"; "a romper el maleficio suizo"; "maldición de victorias"; etc. El cansancio o la mala suerte también se apropian de las mentalidades y del común decir de la gente: "con tanta lesión no se puede jugar", "ayuda divina", "infierno turco" $(A B C, 1 / 04 / 09)$.

Una extensa literatura antropológica sobre los rituales de curación muestra que las enfermedades, además de biológicas, son culturales y sociales. Ponerse una determinada camiseta, vendarse una parte del cuerpo, ungirse con determinadas cremas, hacer necesidades antes del partido, realizar el mismo calentamiento, santiguarse o entrar con el pie izquierdo constituyen auténticos rituales curativos. El trato que la prensa y el equipo técnico da al tema de las continuas lesiones de sus jugadores, se alimenta con discursos de redención y consideraciones fatalistas en el sufrimiento humano: "los sanadores del club"; "las lesiones cambian al equipo"; "vestuario repleto"; "necesidad de chamán"; "mano de santo"; "victorias balsámicas"; "cruzo los dedos para que no sea una lesión grave"; son algunas referencias que nos ilustran este proceder. En todo caso, las lesiones son advertidas por la prensa como un castigo. Pero la deseada "cura espiritual", considerada como una victoria o recuperación del equipo, se puede convertir en la mejor medicina: "Eterno Raúl" (El País, 27/04/09); "Iniesta en los altares" (Marca, 8/05/09); "Iniesta demuestra que los milagros existen. Dios se apareció vestido de amarillo" (Sport, 29/05/09); "A Roma con San Andrés"; "Iniesta llevó al Barça a la final de la Copa de Europa"; "San Andrés (Iniesta) disparó con la fe" (El Periódico, 7 de mayo de 2009); etc. Y es que, como dicen ADAMSON \& WeABER (1985: 539) "es esencial en la magia, la eliminación de toda interferencia para el óptimo resultado deportivo", con indicaciones como severidades en la dieta, en el sexo y otros rituales de sacrificio, tan prolíficos en el campo deportivo. De igual forma KEMP (1975: 365) hablaba de flujo de energía, para definir «cómo se canaliza la energía entre las distintas actividades del grupo con el objeto de que éste sobreviva».

Según lo analizado, las derrotas confieren pérdida de identidad y dan confianza en la suerte y en el destino: las necesarias victorias actúan entonces, en la medida de "ritos curativos", recobrando esa identidad perdida: "victoria balsámica" o "se acabó el embrujo". La protección mágica viene a justificar una derrota clave y el club y el periodismo entonces, achacan fracasos de una semana al "cansancio", "viajes", o al "miedo a la afección de un virus gripal", "al frío", en definitiva, narraciones que dejan atrapar a un público alimentado a través de entusiasmos y enigmas.

\section{Conclusiones}

La idea constatable a lo largo de todo el estudio es que las informaciones periodísticas estudiadas acercan las realidades deportiva y simbólica, es una persistente exaltación de un lenguaje que apela a lo mítico, a lo religioso, a lo bélico, de lo que se desprende que estos deben ser elementos más en el análisis de la información deportiva, cosa que hasta ahora no venía siendo fehacientemente considerado. 
En el período de tiempo analizado, rogativas y lesiones deportivas han ido de la mano, lo que denota una falta de medida por la incertidumbre causada, y eso es debido, a que representan situaciones en las que, como decía MALINOWSKI (1981), se recurre a la magia para que calme esa ansiedad, a pesar de que como apunta GALT (1982: 647), que lo único que se puede observar en este tipo de prácticas, son los rituales y las conversaciones sobre ello.

Metodológicamente, el ACD nos ha permitido articular un procedimiento de análisis juicioso y explícito de las interrelaciones entre las estructuras comunicativas y las estructuras sociales con gran repercusión en la educación. En esta tesitura, creemos que el análisis de las noticias y de los discursos de temática deportiva constituyen un instrumento valedero para articular patrones de conducta y significados de identificación, así como valores que fomentan entre otros, la lealtad identitaria y localista, la memoria comunitaria y valores cívico-moralistas. No obstante, el mito, la historia, la memoria o la identidad aparecen en el periodismo de forma continuada, como ha señalado Duch (2002: 22) y evocan lo ancestral, la totalidad, lo primitivo. En este sentido, la sociedad tradicional, de alguna manera dogmatiza una conciencia colectiva que se construye con un tamiz religioso en el sentido de que aquella dignifica y significa.

En los medios se refleja la sociedad actual, sus compromisos o sus motivaciones. Esto nos hace pensar que son espejo y proyección de la cultura. Y esto nos lleva a plantear que, junto a otros mecanismos de socialización, como son la familia, la escuela o las tradiciones, la prensa escrita resulta un importante marcador social.

Se ha querido dejar constancia de un discurso narrativo que, aunque de manera inconsciente resalte complicidades, queda en la mente de quien lo lee, quien lo oye o quien en definitiva lo sigue, pues como apunta LlOBERA (1996: 246) "lo importante no es tanto la presencia o la ausencia de seres sobrenaturales como la naturaleza preceptiva de las creencias para todos los miembros del grupo".

Es, bajo esta configuración donde el periodismo deportivo reconcilia a los lectores, reconforta a la sociedad y sobre todo, les informa de la existencia de una dimensión mítica, simbólica y religiosa. La propuesta y validación de la experiencia educativa en diferentes centros de Castilla y León, nos ha mostrado cómo la educación en valores debe ser guiada y tutorizada.

\section{Referencias Bibliográficas}

ADAMSON, Edward \& WEABER, Thomas (1985): Antropología y experiencia humana. Barcelona, Omega.

ARMENTIA, José Ignacio; CAMINOS, José María \& MARÍN, Flora (2005): "El lenguaje de la crítica enológica en la prensa española”. Zer, 19, pp. 89-125.

BURKETT, Walter (2009): La creación de lo sagrado. La huella de la biología en las religiones antiguas. Barcelona, Acantilado.

DIJK, Teun A. van (1999): "Critical Discourse Analysis and Conversation Analysis". Discourse and Society. 10 (4), pp. 459-460. 
DIJK, Teun A. van (2000): "El estudio del discurso", en DIJK, T. A. Van (ed.) Estudios sobre el discurso. Una aproximación interdisciplinaria. (2 volúmenes) Barcelona, Gedisa, pp. 21- 66.

DUCH, Lluís (2002): “Antropología de la comunicación”. Anàlisi, 29, pp. 21-40.

DURKHEIM, Émile (1982): Las formas elementales de la vida religiosa. Madrid, Akal.

GALT, Anthony (1982): "Evil Eye as Synthetic Image and Its Meanings on the Islands of Pantelleria, Italy". American Ethnologist, 9, (4), p. 647.

GARCÍA MATILLA, Agustín (2001): "Información, ficción y pedagogía en el fútbol televisado". Comunicar. Revista científica de comunicación y educación, 17; pp. 57-63.

GINESTA PORTET, Xavier (2007): "Los valores en el deporte: una experiencia educativa a través del Barça-Madrid". Comunicar. Revista Científica de Comunicación y Educación, 28; pp. 148-156.

KEMP, William (1975): El flujo de energía en una sociedad de cazadores, Introducción a la Antropología biológica y Social. Madrid, Scientific American- Hermann Blume.

KOTTAK, Conrad Phillip (1997): Antropología cultural. Espejo para la humanidad. Madrid, Mc Grawhill.

LLOBERA, Josep Ramón (1996): El dios de la modernidad. El desarrollo del nacionalismo en Europa occidental. Barcelona, Anagrama.

MALINOWSKI, Bronislaw (1981): Magia, ciencia y religión y otros ensayos. Barcelona, Ariel.

MEYER, Michael (2003): "Entre la teoría, el método y la política: la ubicación de los enfoques relacionados con el ACD". En WODAK, Ruth y MEYER, Michael: Métodos de análisis crítico del discurso. Barcelona, Gedisa, pp. 35-60.

MORAGAS, Miguel de (1995): Mass media e identidad cultural en una época de cambios en la comunicación. Bilbao, Situación, Servicio de Estudios BBV.

MORRIS, Desmond (1982): El deporte rey. Ritual y fascinación en el fútbol. Barcelona, Argos Vergara.

MOSCOSO, David (2005): "La construcción social y cultural del liderazgo en el deporte". Apunts, $\mathrm{n}^{\circ} 79 ; 8$, pp. 5-12.

NEIL, G., ANDERSON, B. \& SHEPPARD, W. (1981): "Superstitions among male and female athletes at various levels of involvement". Journal of Sport Behavior, 4, pp. 137-148.

SÁNCHEZ MARTÍN, Ricardo \& SÁNCHEZ MARTÍN, Jorge (2001): "Culturas deportivas y valores sociales: una aproximación a la dimensión social del deporte". Apunts, 64, pp. 33-45. (Monográfico: Humanismo en el deporte).

SEBRELI, Juan José. (1998): La era del fútbol. Buenos Aires, Editorial Sudamericana. 
SHINAR, Dov (2000): "Media diplomacy and "peace talk: the Middle East and Northern Ireland". Gazette: the International Journal for Communication Studies, 62 (2), pp. 83-97.

VALDANO, Jorge. (1986): “El miedo escénico". Revista de Occidente, n 62-63, Madrid, pp. 103-109.

WEISS, Gilbert. \& WODAK, Ruth (Eds., 2002): Critical Discourse Analysis. Theory and Interdisciplinarity. Palgrave, Macmillan.

WILLIAMS, Raymond (1984): The long Revolution. London, Penguin.

WODAK, Ruth (2003): "De qué trata el análisis crítico del discurso -(ACD)- Resumen de su historia, sus conceptos fundamentales y sus desarrollos". En WODAK, RUTH. \& YOUNG, Kevin (1993): "The Killing Field: cuestiones que suscita el tratamiento dado por los medios de comunicación de masas a los disturbios del estadio de Heysel", en Barbero, J. Ignacio. Materiales de Sociología del Deporte. Madrid, La Piqueta, pp. 167-186. 